\title{
Lo sagrado en las sociedades secularizadas
}

\author{
SANTIAGO GONZALEZ NORIEGA \\ Universidad Autónoma de Madrid
}

La potencia tutelar burocrática asume la custodia de una masa amorfa. Frente a ella ha de afirmarse una sociedad civil a partir de núcleos de ciudadanos activos. El motor de esta ciudadanía es la formación de un núcleo básico de creencias - «lo sagrado»- que desempeña un papel comparable, en cuanto a capacidad de movilización. al de las viejas religiones. Lo sagrado slaicon o "filosóficon apunta a aquello que el hombre puede considerar perdurable y conferir sentido a su existencia.

\section{Concepto y critica de la 'sociedad civil'}

Como es sabido, el concepto de 'sociedad civil' es uno de los conceptos fundacionales de la moderna ciencia social y de la teoría política. ${ }^{1}$ Aparte de su utilización —en un sentido diferente del que ahora ticne- por autores como el ilustrado escocés Adam Ferguson, el sentido actual de 'sociedad civil' proviene de los escritos de J.G.F. Hegel y fue empleada por primera vez en los borradores de la Enciclopedia de las Ciencias Filosóficas, que datan de 1817. Hegel distingue entre el Estado y la sociedad civil, compuesta por individuos que se centran en la prosecución de sus intereses particulares sin preocuparse expresamente del bien general, aunque éste se produce, según él, al término de una complicada dialéctica que eleva el trabajo individual a trabajo abstracto, trabajo social. Moralizar a esta multitud egoísta es imposible, de ahí la necesidad de poner en una instancia superior el cuidado de los más altos ideales y constituir a una clase, los funcionarios - la clase universal, como los llama Hegel en la Filosofia del derecho- en guardianes del interés común. A partir de Hegel se desarrolla una paradójica criatura: una "sociedad civil» cuyos "ciudadanos», que son trabajadores y gozadores solitarios, no tiene "ciudad», y que se integra en virtud de la acción exterior de una potencia tutelar pretendidamente altruista, depositaria del verdadero interés de los «ciudadanos». (Sólo podemos apuntar aquel que tal escisión, con su glorificación de los ángeles guardianes burocráticos, encontrará su última expresión en la concepción leninista del Partido.) Mientras que en Aristóteles (Política, L. III, 1) el ciudadano se definía por la simultánea asunción de los dere- 
chos y de los deberes de la ciudadanía y por la participación en el ejercicio del poder público, en el moderno concepto de ciudadano como miembro de la sociedad civil el ciudadano pasará a ser titular de derechos concedidos por el Estado y a estar sometido a la tutela casi eclesiástica de éste. Al no reconocer el individuo que derechos y deberes son indisociables pone al Estado como responsable de su custodia, y al no asumir las responsabilidades de gestión de los asuntos públicos, creyendo ganar el apacible disfrute de su mundo propio lo que hace es renunciar por completo a aquellas parcelas de poder y conocimiento que harian de él un verdadero ciudadano. (Como en tantas otras ocasiones el Hegel maduro parece olvidar lo que -antes que B. Constant- ya sabía muy bien cuando escribió los escritos de juventud, impropiamente llamados «teológicos».)

\section{Sociedad civil y ciudadanía activa}

El propósito fundamental de este escrito es intentar replantear el problema de una redefinición de la sociedad a partir de la existencia de una ciudadanía activa, esta redefinición intenta mantener el momento de lo individual, pero tan sólo como una fase en la constitución de la ciudadanía autónoma. Para nosotros, en una situación de ausencia de una auténtica comunidad política, de una "ciudad», el único camino hacia su reconstrucción es el de la existencia de una sociedad civil a partir de núcleos de ciudadanos activos que llevan a cabo una acción colectiva que podemos caracterizar como sigue:

a) la acción colectiva se orienta por tomas de posición teóricas de individuos,

b) dentro de pequeños grupos con una voluntad de participación política,

c) reteniéndose el momento individual al considerarse que los aspectos teóricos fundamentales, ideales ético-políticos y consideraciones filosóficas de tipo general, han de provocar el más profundo asentimiento en el fuero interno.

Estas cuestiones irán aclarándose —espero- en las páginas siguientes.

Dejo de lado una posibilidad que me parece interesante y que, por fortuna, va teniendo cada vez más el carácter de lo pasado, excepto en el caso de las situaciones que se dan en los reinos de notorios megalómanos como el Gran Líder, su hijo y heredero, el Querido Dirigente y el Líder Máximo. Como es obvio, me refiero a una acción próxima a la que estudiamos y es la que los "disidentes» en los países del Este y de lo que les hizo resistir contra toda esperanza: a la de escritores como Chalamov o, 
mucho más aún, a oponentes como un Vaclav Havel. Así pues, me limitaré a tratar de las acciones que surgen dentro del marco de posibilidad de las sociedades democrático-liberales occidentales.

\section{En el origen de la sociedad civil: establecimiento de una conciencia autónoma en Descartes y Locke}

Comencemos por destacar el «momento individual» de la sociedad civil, especialmente en relación con la tradición filosófica, un momento en que la filosofía es primordialmente ruptura con la tradición pues nuestra tradición, la que ahora consideramos, es, ella misma, nuptura con una tradición anterior que presentaba su propio carácter inconmoviblemente duradero como garantía de fiabilidad y venerabilidad. Dos caminos se presentan aqui, ejemplares, para el individuo en su esfuerzo por autodeterminarse y hacer posible su acción coordinada en ruptura con lo aceptado: el primero -el de un Descartes- lleva directamente a la formación de una comunidad no-política de investigadores y filósofos $\mathrm{y}$, en su forma extrema, se concibe un siglo más tarde como "conjura" de unos pocos a los que ha alcanzado la luz de la verdad; el segundo, el de John Locke, es menos radical en sus conclusiones pero tiene algo que le falta a Descartes: una voluntad de determinación de la esfera pública y de su límite con respecto a la esfera privada.

Comencemos con el primero. Lo heroico en Descartes es su capacidad de soledad, su desconfianza de todo lo aceptado y, al mismo tiempo, su capacidad de goce del conocimiento. Es un guerrero que avanza con la sola fuerza de su mente ante fantasías paranoicas: ¿un Dios bondadoso o un Dios malvado que pretende engañanos, el genio maligno? ¿una tradición que es tesoro de sabidurías pasadas o puro engaño? Ante estos espantosos dilemas sólo tiene una mínima isla de seguridad y amparo, el espacio es bien exiguo pero la plaza fuerte es inexpugnable: el cogito como fundamento de la verdad. Por el cogito se separa el sujeto de Dios y se pone, en lo que a la verdad de la conciencia respecta, en un plano de igualdad total con él: "Engáñeme el genio maligno cuanto quiera; hasta aquí, hasta lo más interior de mi conciencia, no alcanza su poder». Por el cogito se separa también el sujeto de su propia comunidad por cuanto ésta se funda y asienta en el crédito otorgado a unas verdades transmitidas por la tradición tenida por venerable; «lo que vosotros aceptáis sin más, crédulamente, eso mismo yo no lo hago mío; en esto no os sigo ni soy de los vuestros; aquí camino solo y además os dejo el relato de mi aventura, os señalo indicadores que hacen fácil el camino y hasta me olvido del mérito que pueda tener mi osadía»: "Mi propósito no es enseñar aquí el método que todos deben scguir para conducir acertadamente su razón, sino solamente hacer ver de qué modo yo he tratado de conducir la mía ". Aquellos 
que, como los neoconservadores de ahora y los tradicionalistas de antes, exigen el respeto absoluto a la tradición hay que replicarles haciéndoles ver cuán poco una y única es la tradición, cómo se define uno a sí mismo en la «inocente» operación de elegir una tradición y no otra y cómo para muchos es tradición y enseñanza precisamente la crítica de toda tradición y enseñanza. "La razón como constante de la humanidad tiene un denominador común: su continua autoconstrucción, su permanente autocrítica. Éste es el momento ilustrado siempre insatisfecho. ${ }^{3}$

A Descartes le eran aviso de que entraba en terreno peligroso la hoguera de Bruno en el "Campo de las Flores" de Roma y el tribunal de Galileo. Poca tradición de mártir tenía este valiente; hay que ir con tiento; defender el mensaje pero no a expensas del mensajero. Pero, insisto, hay que ser cauto: su lema era Larvatus prodeo, avanzo enmascarado. Hay que cscoger como residencia el país más libre de la época, la Holanda que será patria y refugio de Spinoza y de Bayle. No basta con ello, el filósofo hace además un "pacto con el mundo" en el que se mezclan la desconfianza, el tiento y también el sentimiento de la complejidad del asunto; para hacer posible una actividad filosófica y científica libre e indisturbada por los poderes públicos político-eclesiásticos hay que adoptar una moral provisional. De momento el filósofo deja de lado la transformación directa de la sociedad entera (si no es por el camino del progreso técnico), pero establece por primera vez a un individuo separado de la sociedad y la tradición, y no necesitado de tutela alguna en el terreno del conocimiento: una realidad separada con capacidad de juicio plenamente propio, con un fuero interno de cuyo desarrollo surgirán esos poderes independientes sin los cuales es imposible una sociedad realmente secularizada.

En este breve esbozo de la historia de los orígenes del individuo autónomo moderno otro de los grandes maestros es John Locke, cuya filosofía supone un progreso en la autonomía con respecto a Descartes. Locke no pacta con la sociedad sino que pretende dirigir sus tiros a un mundo dominado omnicomprensivamente por la dimensión político-eclesiástica. Lo que en Descartes es el espacio individual de la conciencia filosófico-científica se convierte en Locke en espacio privado como algo claramente diferenciado de lo público, en un ámbito en el que el individuo tiene pleno derecho frente a cualquier autoridad espiritual o temporal.

La sociedad no es ya una grey uniforme en el predio de reyes y obispos; el individuo tiene una esfera propia, intangible: las cuestiones de fe; $\mathrm{y}$, lo que no es menos importante, los individuos no sólo tienen un derecho inviolable a tratar las cuestiones religiosas como tengan a bien en su fuero intimo, sino que tienen igualmente un derecho no menos inviolable a asociarse con otros individuos a fin de obtener una aclaración en los asuntos últimos de la existencia humana; dentro aún de la identidad, bien cuestio- 
nable, entre lo religioso y el problema del sentido, la esfera de lo público ha de autolimitarse, y si no lo hace pierde su legitimidad, y aceptar junto a ella, y con su mismo rango, una esfera privada cuyo contenido son las cuestiones religiosas, los asuntos de fe. Locke llama "Iglesia" -aunque nosotros emplearíamos más bien el término "secta" - a la sociedad que surge de ese propósito de logro de la claridad en asuntos de fe. Escuchemos al propio Locke: «[...] todo el poder del gobierno civil se refiere solamente a los intereses civiles de los hombres, se limita al cuidado de las cosas de este mundo y nada tiene que ver con el mundo venidero.

"Consideremos ahora qué es una Iglesia. Estimo que una Iglesia es una sociedad voluntaria de hombres unidos por acuerdo mutuo con el objeto de rendir culto públicamente a Dios de la manera que cllos juzgan aceptable a El y eficaz para la salvación de sus almas.

"Digo que es una sociedad libre y voluntaria. Nadie nace miembro de una Iglesia. ${ }^{4}$

"[...1 la Iglesia en sí es una cosa absolutamente distinta y separada del Estado. Las fronteras en ambos casos son fijas e inamovibles» (p. 23).

"Cada hombre en esto [en lo que concierne a su propia salvación] tiene la autoridad suprema y absoluta de juzgar por sí mismo. La razón es que a nadie le concierne este asunto ni nadie puede recibir perjuicio alguno por su conducta en esta esfera» (p. 50).

Ciertamente, la posición de Locke tiene una limitación básica: la exclusión de los ateos de la sociedad civil, exclusión que se mantendrá hasta la "religión civil» del Contrato Social (IV, 8), pero que desaparecerá en Jefferson, para quien basta con tener "sentido moral" para ser miembro de pleno derecho de la comunidad política.

\section{El concepto tradicional de lo sagrado y la tesis de la secularización}

Al igual que el concepto de lo sagrado que trataremos más adelante de oponer al concepto tradicional del mismo, éste es pensado como designando lo superior en cuanto a valor e importancia y, en cuanto tal, objeto de reverencia. Pero mientras que para nosotros lo sagrado es algo que tiene que impregnar progresivamente a su otro: lo profano, lo cotidiano, elevándolo a su dignidad o desdramatizándose a sí mismo, para la concepción tradicional de lo sagrado su carácter sacro se manifiesta precisamente en el corte abismal que lo separa de su otro. Este corte, esta distancia infranqueable se enfatizará diciendo que las cosas sagradas «son absolutamente distintas" de las profanas, "están infinitamente por encima de ellas", son divinas o, al menos manifiestan lo divino en lo sensible (..., objetos de culto, textos religiosos). Ya hemos dicho la palabra clave: lo sagrado tradicional es lo religioso, lo que es manifestación máxima de lo divino. Trátese de los relatos de los Ancestros de los primeros tiempos o de la Misa cris- 
tiana lo que se consigue es una repetición simbólica de lo que fue, en el principio de los Tiempos o en el momento culminante de la Historia; de ahí recibe lo sagrado su fuerza sacral. En cuanto tal, lo sagrado $-\mathrm{y}$, a partir de ahora cuando, sin más precisión, empleamos el término habrá de entenderse como equivalente a "sagrado tradicional" - lo sagrado, pues, es algo separado, prohibido, inviolable, y algo idéntico a las "cosas religiosas». Buenos ejemplos de lo sagrado son los misterios judeo-cristianos: ¿por qué el hombre no debe probar del árbol del bien y del mal?, ¿por qué el Hijo debe pagar una deuda, cómo no, «infinita» que los hombres tienen con Dios (Redención)? No hay que poner en duda ni someter a crítica nada; ante estos "Misterios" el pensamiento debe detenerse, no puede aplicar las reglas que sirven para entender su experiencia habitual o sus mismas instituciones morales o legales. Otro buen ejemplo de lo sagrado y de la actitud que se supone ha de tener ante él el hombre lo encontramos en el mandato divino (vgr., en los «mandamientos de la ley de Dios», pero también en las prescripciones rituales): por qué no he de robar, porque lo manda Dios, por qué no puedo comer cerdo y sí cordero, porque lo manda nuestra religión. En todos estos casos encontramos una limitación y casi una paralización del poder personal: del poder de pensar y de obrar. En este sentido creo que son acertadas las palabras del filósofo político francés Marcel Gauchet que caracterizan la religión con estas palabras: "[la religión] es una desposesión radical de los nombres en cuanto a lo que determina su existencia y $[. .$.$] una permanencia intangible del orden que les mantiene$ unidos. No tenemos nada que ver con lo que es. Nuestra manera de vivir, nuestras reglas, nuestros usos y lo que sabemos es a otros a quienes los debemos, a otros que son seres de una naturaleza diferente de la nuestra -Antepasados, Héroes, Dioses-y que las han establecido o instaurado. Nosotros no hacemos más que seguirlas, imitarlas o repetir lo que nos han enseñadon. ${ }^{5}$ Un buen ejemplo en el que se ve lo que de ordinario queda oculto en lo sagrado religioso es el del relato de la fundación mítica de Roma por su primer rey. Una vez Rómulo ha trazado los límites imaginarios de la futura Urbe éstos son sagrados y quien no los respete conocerá el poder del filo de la espada. Pero en este caso la fundación es real, se da en un momento de este tiempo y el calendario tendrá en ella el inicio del cómputo de los años en tanto Roma sea poderosa, y sólo será poderosa mientras entienda y respete sus instituciones. Con su acto, además, Rómulo hará ver a Remo, y con él a todos los romanos, que la Ciudad es superior a la familia, y que las instituciones valen más que la sangre, aunque sea la sangre de un hermano, dando a sus súbditos mores et moenia, costumbres y murallas, para recordar las palabras de Virgilio (el relato del mito de la fundación de Roma puede encontrarse bellamente expuesto al comienzo de $A b$ urbe condita de Tito Livio).

Los dogmas y los mandatos religiosos constituyen sistemas de orienta- 
ción vital con capacidad de movilización, con una enorme capacidad para conseguir que los hombres actúen de forma diversa a como lo han hecho hasta conocerles o para atenerse a lo que dogmas y preceptos ordenan (el dogma no es más que un pensamiento a cuya verdad se ordena asentir plenamente, ciegamente). Basta comparar su capacidad de movilización con la que tiene la filosofía para darse cuenta de la exactitud de lo que digo; las éticas helenísticas llegan a unos pocos sabios, el cristianismo arrasa el mundo feliz del paganismo y termina instalando sus reales donde fue martirizado el primer pontífice y el sucesor de Pedro llega a reinar sobre el corazón del Imperio, los Estados Pontificios.

Pero, ¿acaso tienen las religiones una función civilizadora que compense de alguna manera esta enajenación que las funda? Es ésta una compleja pregunta; sólo podemos responder con algunos apuntes que dejan abierta la cuiestión que no podemos ni tratar aquí con detenimiento ni dejar de mencionar siquiera sea de pasada pues es un eslabón que nos lleva a la tesis sobre la secularización.

No hace falta haber leído a Nietzsche para darse cuenta de qué valores morales colocó inicialmente el cristianismo en el centro de su predicación y de cómo esos valores persisten casi intactos en autores que o no son ortodoxos o incluso se tienen a sí mismos por enemigos del cristianismo o, al menos, oponentes del mismo. ¿Pero, aunque admitiésemos que tales valores son en verdad centrales en la doctrina cristiana, es que acaso tiene el cristianismo la patente de su invención o la de su puesta en práctica? Pensemos en el mundo del Antiguo Régimen: qué tiene que ver el Evangelio con los beneficios eclesiásticos, los derechos de pie de altar, las rentas de los ministros del Señor (en España, el primer rentista es el arzobispo de Toledo). Al mismo tiempo, los enemigos reales o supuestos del cristianismo como el archienemigo Voltaire exponen una moral depurada próxima a la del Evangelio. Volviendo a nuestro país, ¿dónde encontrar al cristianismo en esos obispos infatuados, llenos como odres de vino de hipocresía y vanagloria cuyos retratos aparecen tantas veces en la cubierta de revistas como la Ilustración Europea y Americana, o en autores como Clarín o Pérez de Ayala?

La teoría social clásica entendió la modernidad como paso de la religión a otra cosa que venía a superarla: la teoría de los estadios en Comte, la de-magificación (Entzauberung) y racionalización de Weber, el núcleo moral de los derechos humanos en Durkheim. En todos estos casos, y en muchos otros, la religión era cosa del pasado. Nosotros estamos muy lejos de compartir ese optimismo; la muerte de la religión laica marxista es contemporánea del renacimiento de fundamentalismos de todo tipo, el árabe, por supuesto, el más conocido y temible para nosotros, pero también el hinduista o el de la derecha americana con sus predicadores televisivos. 
Vivimos, se nos dice una y otra vez, en un mundo "sin utopías" (y, para cualquiera que haya leído a los clásicos del género de política-ficción de las utopías, no parece que sea cosa de lamentarlo). Pero quien de tal cosa se lamenta dice con ello otra cosa muy distinta: vivimos sin norte y sin guía, el dinero es nuestra más clara y comprensible meta, algo que incluso permite que nos sean comprensibles las acciones de los otros, un principio de inteligibilidad de los actos humanos: tal persona hace tal cosa porque así ganará más dinero, o tendrá dinero de forma más segura, o realiza "una buena inversión»; los políticos, ya se sabe, "son todos más ladrones», "van todos a lo mismo». En esta confusión, son muchos los que creen que hay que volver a lo sagrado tradicional: a la religiosidad cristiana en su forma prístina (como aquí en España un José Aumente), a las religiones exóticas o, en algunos casos, a sectas minoritarias que absorben por entero la vida de sus miembros y les descargan del pesado fardo de su soledad responsable.

Proponemos aquí, frente a estas formas tradicionales de lo sagrado, un nuevo concepto de lo sagrado (una formulación que es próxima, por ejemplo, a la idea del filósofo y político greco-francés Cornelius Castoriadis, de una "auto-institución» de la sociedad). ${ }^{6}$ Como ya hemos avanzado en la superación de lo religioso no creemos que ésta haya de realizarse como libertad total en el mal (Sade) o como ausencia de todo freno (Antifón); por lo mismo, no creemos con Tocqueville que la dependencia religiosa sea la condición de la independencia política, esto es, de la democracia.

El nuevo concepto de «sagrado» que proponemos, y del que hemos de ocuparnos en las páginas que siguen, está entregado a la reflexión y a la decisión de individuos que participan en una búsqueda común en la que no se piden asentimientos radicales, ni se da un crédito inagotable a nadie. La búsqueda es común pero no anula la apelación última al fuero interior, ni hace de éste una dirección infalible ni excluye el retorno a la validación intersubjetiva por medio del diálogo, aunque sea privilegio de los muchos errar con la misma facilidad con que se extravían los caminantes solitarios. No queremos ni Jefes, ni Maestros; quien aspire a reinar solo váyase con sus coronas y su música a otra parte. De la filosofía retenemos el momento en que fue palabra en el ágora pero despedimos al hábil sofista que tan bien sabe llevar el agua a su molino. Queremos hablar, cuando sea posible y muchas veces lo es, con palabras comunes, por más que lo que digamos sea difícil de entender: la claridad de lo dicho no exime del esfuerzo de pensar. ¿Cómo llamaríamos a este nuevo concepto de lo sagrado, alejado por igual del dogma y el mandato? Creo que una buena manera de nombrarlo sería hablar de lo "sagrado filosófico" o de lo "sagrado libre». Tratemos de aclarar lo que decimos en las páginas que siguen. 


\section{Lo sagrado no religioso}

Joan Baez decía en una bella canción de los años sesenta: «Amor es una palabra de cuatro letras". Lo mismo sucede con casi todas las palabras que verdaderamente nos importan: que son un soplo, un inicio y, también, un enigma. Signos, garabatos. Y, precisamente, por eso pueden medirse con nuestra propia existencia, por eso puede reflejarse en ellas nuestra existencia que, como ellas, es luz y enigma. El significado fluye incesante en las palabras; querer detenerlo es matarlo. Sólo son nítidas, como cortadas a cuchillo, palabras que nombran cosas que no nos importan mucho: taza o prismáticos, oligisto o retracto; y son nítidas porque nombran nuestros útiles o nuestras clasificaciones; nos obedecen porque primero hemos hecho de ellas siervos obedientes. No otro tanto sucede con aquellas en que nos va la vida, en las que nos ponemos en juego enteramente: amistad, honor, muerte o la propia palabra vida. Al usarlas nos perdemos o nos ganamos, y entender que el equívoco acecha y también el engaño es una primera y dolorosa lección de sabiduría. Bien sé que no ocurre exactamente lo mismo con la palabra sagrado; unos - poco versados en la ciencia de las religiones o que, simplemente, no frecuentan mucho los diccionarios de nuestra lengua - creen ver en ella un cierto tufillo religioso y hasta sacerdotal; otros están más cerca de la verdad cuando dicen aesto es sagrado para mín, bien que, con buen criterio, tendemos a callar, y no a desparramar en palabras, lo que verdaderamente nos importa. Muchas veces hasta vemos un sacrilegio en el uso que otros o nosotros mismos hacemos de palabras que ponen al descubierto ese fondo último de lo que tenemos por máximamente valioso y aun preferimos callar toda la vida antes de permitir que otros, y aun nosotros mismos, penetren en ese santuario interior. En lo que sigue, "sagrado" habrá de entenderse, más que como una palabra que denote una realidad inequívoca, como un indicador de múltiples y divergentes caminos. Sírvanos pues la expresión ulo sagradow como un índice que apunta a dos ideas básicas que trataré de definir brevemente:

1) No todas las realidades son del mismo orden: A. Machado dijo sobre esta verdad tan conocida una frase que me exime de más comentario: "Todo necio confunde valor y precio".

2) Hay ciertas orientaciones de valor, ciertas decisiones básicas en las cuales se arriesga la relación de uno mismo a estas realidades supremas, y en las que puede resultar necesario poner en peligro incluso la propia existencia para no perder la relación fundamental que con ellas se tiene. Casi siempre no es uno quien se pone a sí mismo en esa situación de peligro pero si se ve ante ella sabe decidir: no perder las causas para conservar la vida, como decía Propercio en un verso muy querido por Kant: 
"Y por vivir la vida, perder las causas». En tales situaciones alguien puede tener su hora de gloria y enfrentarse con valor a la muerte leyendo a sus alumnos la Declaración de los Derechos del Hombre de 1791, como le ocurre al protagonista del filme de Jean Renoir Ésta es mi tierra (1943), que conquista así el derecho a llamarles a ellos y a sí mismo ciudadanos. En tales situaciones límite, y aquí volvemos al atroz mundo real, se puede responder como hizo en 1944 el ilustre matemático y activo miembro de la Resistencia francesa, Jean Cavaillés, a los nazis que le iban a fusilar y le decían «Usted va a morir" con la simple constatación que encierra esta respuesta: «Sí, pero la verdad no muere nunca».

Pero alejémonos de la sangre que a veces se cobra el valor cívico. No es ésta la única forma de manifestación de lo sagrado en la vida de los nombres. No olvidemos el valor de quien espera lo mejor de sí antes de ir descubriendo si es o no capaz de darlo, el valor de quien, como T.E. Lawrence, castiga su cuerpo para ser dueño de su espíritu, el valor de quien enfrenta la adversidad sin perder la alegría, el valor, el más humilde y conocido valor, que tantas veces es preciso cada mañana para seguir viviendo.

Mi pregunta es ésta, ¿de donde viene la energía que nos hace esforzarnos por vivir con dignidad en un mundo en donde esto es todo menos fácill? ¿Qué ideas, qué creencias, son fuente de orientación intelectual en ese afán?

Hemos visto que el momento individual de constitución de una subjetividad separado de la tradición (Descartes) y de un Estado que deja en manos de los individuos la elucidación de los problemas básicos de la vida (las cuestiones que entonces se denominaban "religiosas") es un momento insoslayable de la constitución de una subjetividad libre con un ser propio, autónomo. ¿Hemos de detenernos aquí? ¿Sólo es sacro el espacio de intimidad de la subjetividad, lo más personal y reservado de la dimensión privada de la existencia? Si admitimos esto entonces el liberalismo más puro es la última palabra de la sabiduría, y para muchos parece que en ello estamos. Cierto, este espacio de intimidad es inviolable, este logro, que no es el del liberalismo en sentido más estricto, sino una de las conclusiones de la cultura política del Occidente moderno (hasta ahora, quizás la más importante de ellas); los bien semcjantes totalitarismos del siglo $\mathrm{xx}$, de este siglo-pesadilla del que parece que estamos saliendo, han sido derrotados, militarmente, uno, denotado por su propia incuria e incompetencia el otro. Pero no es hora de festejos o, mejor ya hemos tenido nuestro festejo con ese asombroso comunista, Mijail Gorbachov, que creía en el marxismo donde ya nadie creía y que le sometió a la prueba de fuego de la libertad sólo para ver cómo se derrumbaba como un castillo de naipes. El unánime triunfalismo liberal del momento apela a la reflexión y a un exa- 
men del estado de cuentas. Y volvemos a la pregunta de unas líneas más arriba: ¿son coextensivos lo sacro y la intimidad no coaccionada?

Llegados a este punto me planteo dos cuestiones, ambas señalan en la dirección una insuficiencia teórica básica de la postura que examinamos: falta tomar en consideración otros elementos de la tradición que no sean los de la filosofía ilustrada y sus orígenes cartesianos, falta tener en cuenta lo imposible que le resulta al individuo solo, aislado, sostener una relación con ese espacio indeterminado que llamamos, aquí y para clarificación de quien esto escribe y de quienes hayan de leerle y escucharle, "lo sacro", "lo sagrado". Retornemos al ejemplo anterior de la muerte de Jean Cavaillés. Imaginemos por un momento que sólo él, de entre todos los franceses, hubiese querido hacer frente a los alemanes, que todo lo demás no fuera sino traición y olvido. Es bien evidente - y sólo lo menciono para que alguien no piense que los tiros van por ahí, y discúlpeme el lector-, es bien evidente digo, que no podría oponer nada a los ocupantes, que si se decidiese a actuar sólo podría tener una acción de kamikaze. Pero lo más probable es que no quisiera actuar, que no pudiera actuar paralizado como estaría por la desesperación de carecer de «ciudad» (en el sentido de polis), de patria, pues no quiero abandonar esta noble palabra a los matones y a su fanfarria. El suicidio podría ser para él la salvación de la locura. Lo que se da no es un resistente aislado, sino la Resistencia, y ésta, a su vez, surge de la acción de hombres aislados o de pequeños grupos que tienen la certeza de que otros seguirán sus pasos, de que serán secundados. Como tantos otros antes que yo creo que es imposible vivir sin esa certeza. ¿Que a qué voy? A recordar el sentido inicial de la palabra «idiota»; para los griegos, el idiotés es el que cree que puede vivir sin comunidad con otros seres o con la sola comunidad del cosmos o de su pequeña y privada comunidad: su familia, sus allegados. Como ya señalaron $B$. Constant o Tocqueville, lo que era desdicha para el antiguo griego es hoy hogar y nido de los modernos: lo público sólo debe garantizar el goce y el disfrute en lo privado, no hay un encuentro comunitario de los hombres.

Antes referí dos ejemplos de valor cívico, real uno, y no menos real, ahora que víctima y verdugo son ceniza, el segundo, el que algunos creen que hay que menospreciar porque es, nos aseguran, «meramente literario». Ahora quiero descender de esas situaciones extremas: el que salva a alguien de morir ahogado, el que entra en una casa en llamas para auxiliar a alguien que no ha visto nunca en su vida y del que podrá despedirse con un simple apretón de manos. Quiero llevaros ahí donde más difícil parece demorarse a los humanos: en los trabajos y la herrumbre de los días, en la fatigada cuenta de los años. ¿Cómo insuflar en esa materia el ímpetu de los momentos de gloria, de los que pocas veces vienen pero que si se convierten en actos nos amparan toda la vida con el orgullo de lo que fuimos? Para volver a nuestra terminología, se trataría de impregnar lo cotidiano de lo sacro. 
En el curso de una vida queremos de verdad a muy pocas personas, estimamos y apreciamos a otras cuantas, nos unen vínculos de afecto quizás más amplios, pero creo que no es exagerado decir que la mayor parte de la gente nos es más bien indiferente, que somos bien tibios hacia ellos; esto no quiere decir que queramos su mal o nos duela su bien, salvo si somos malintencionados o envidiosos: quiere decir que nuestros sentimientos no son lo suficientemente fuertes como para llevarnos a una acción positiva en favor de ellos. ¿Cómo entrar en relación con estos otros, que son la inmensa mayoría, pero también una mayoría casi abstracta? Sostengo, y es ésta una de las tesis de este escrito, que la penetración del espacio público ya por asociaciones voluntarias que actúan en las numerosas áreas descuidadas por el Estado, ya, y, esto es mucho más difícil, pero también insoslayable, entrando de lleno en la esfera estatal, sea por la creación de una opinión pública ilustrada y combativa, sea por medio de partidos políticos, o lo que es más probable y más urgente, a través de nuevas formas políticas del tipo de las que empiezan a anunciarse ya en la Europa continental (aunque no en España).

Dos formas de comunidad, pues, que se apoyan y se refuerzan mutuamente, un espacio privado, donde siempre es posible la libertad del posible retorno a la intimidad, se fortalece convirtiéndose en realidad en lo cotidiano (pienso, por ejemplo, en la causa de las feministas, esté incluida o no en los movimientos así llamados; o la transmisión de valores a los hijos, indispensable cuando la educación se ha degradado y descargado de responsabilidad al aceptar ser sólo enseñanza, «Instrucción Pública»).

A su vez, lo público, en cuanto ámbito de acción de la individualidad que busca romper su clausura en la soledad o en la tribu -en esa "piña» que tantas veces es la familia - da una continuidad a esas orientaciones supremas de valor, de las cuales, de otro modo, estamos siempre en peligro de alejarnos, con grave daño para ese reducto privado que pretendemos proteger. Luchar contra el olvido, sentir en nosotros no sólo la sangre de nuestros primos o nuestros tíos, sino, también, la de Bach o Kant, la de Valle-Inclán o Quevedo, e igualmente la del que observó el nacimiento de una nova o capturó una nueva especie de mariposa.

Fidelidad a lo aprendido de nuestros primeros mayores, las «personas mayores" de la casa, pero sólo en la medida en que de ellos nos venga una primera enseñanza y un ejemplo provechoso, que a tantas gentes habitan las sombras de los muertos y tantos son los que en su primera juventud se pararon para no ser ya más que lo que ya habian sido, o lo que otro fue, que allá se va una cosa con otra. Una vez más Marco Aurelio es un guía excelente cuando, en las primeras líneas de sus Meditaciones, da constancia de lo que aprendió en su infancia de sus allegados y de su maestro; así comienza su obra, con esta concisa lista de reconocimientos que ocupa las primeras páginas del libro: «De mi abuelo Vero: el buen carácter y la sere- 
nidad. [...] De mi madre [...] la abstención no sólo de obrar mal, sino incluso de incurrir en semejante pensamiento. [...] De mi preceptor: el no haber sido de la facción de los Verdes ni de los Azules».?

Público y privado existen, pues, como dimensiones separadas, pero debemos mantener a ambas en interrelación. Quien abandona lo público a tiranuelos de toda laya y a sus secuaces (diciendo, y es el colmo, que son "los políticos» como si dijese que son "las iguanas» y que han caído del cielo como una plaga, como un malévolo maná del desierto, y no de la tierra y más concretamente en la forma del voto que nuestro "hombre digno" y otros como él depositaron en las urnas), quien abandona lo público, pues, se condena a una creciente insensibilidad moral ante lo público que penetra en su casa a la hora del almuerzo y con el inofensivo título de "Noticias sobre el curso del mundo en general y de España en particular». Quien, por el contrario, abandona el cuidado de lo íntimo encuentra en su lugar sustitutos como el de ser comisario político de cualquier lugar donde haya mando disponible, y hay muchísimos, o el fanático del trabajo o el consumista refinado, el que atesora dinero o el que acumula éxitos llamados «amorosos», el que escopeta en ristre sacia su deseo de muerte en la bestia que tiene la libertad que a él le falta.

Frente a estas formas de la ausencia creo que es bueno recordar la idea de empresa en el sentido de Hannah Arendt; para ella la empresa, la tarea común, el proyecto de transformarnos a nosotros mismos y al mundo, es el lugar de emergencia del poder colectivo de acción, poder que sólo dura mientras dura el esfuerzo y «desaparecerá cuando, por la razón que sea, se dispersen o se separen" aquellos que la empresa ha unido. ${ }^{8}$ Entiendo que empresa en este sentido es un grupo ecologista, pero también una pareja de enamorados que quiera dar - si tal cosa hay- duración a su amor. Resta examinar, y trataremos de hacerlo en lo que sigue, cuáles pueden ser el origen y los contenidos de lo "sagrado" a lo que me refiero en este escrito, prestando especial atención a las tradiciones filosóficas y literarias de las que es deudor.

\section{Lo sagrado y el sentido de la vida}

En lo que sigue trato de poner de relieve la naturaleza social y política de una cuestión que siempre ha sido considerada como el arquetipo de "lo privado", y hasta de lo íntimo: la cuestión del «sentido de la vida». Mucho se ha escrito sobre esto pero, a lo que se me alcanza, los que se han ocupado de esta cuestión lo han hecho partiendo de un punto de partida básicamente erróneo, viciado por la necesidad que tiene todo acto de expresión verbal de generalizar, de poner la experiencia individual en términos válidos para todos y comprensibles por todos. Empecemos por prestar atención a la propia expresión de «sentido de la vida» que es usada como 
si el sentido y el valor de la vida fueran uno solo, como si hubiese una única manera de apreciarlo. Para algunos, como Schopenhauer, "vivimos en el peor de los mundos posibles»; para otros, y no sin cierta exageración y cierto abuso de la zalema teológica, vivimos en el mejor de tales mundos (como es bien sabido excedió en tales enseñanzas el filósofo Leibniz, pero son un modesto remedo de las mismas los sermones de tantos predicadores televisivos: «todo está un poquito mal, pero ya veréis, querido rebaño, cómo enseguida se pondrán las cosas de maravilla, derramará mercedes el Omnipotente sobre nosotros los justos, y penarán y sufrirán como es debido los malvados"). Entre estos dos extremos de Schopenhauer y Leibniz se movió la historia de la filosofía al ocuparse de esta cuestión. Más prudente, el gran David Hume, con su habitual clarividencia, entendió que ningún viaje cósmico nos permite la comparación de la que resultarían esos extraños superlativos absolutos: «el mejor», "el peor» (¿cómo podría alguien aftrmar que algo es lo mejor de todo sin conocer lo demás?). Lúcido, Hume se limitó a decir que éste nuestro mundo es uno de los posibles y que en él más que Dios parece reinar Fortuna rcpartiendo al azar bienes y males.

Pero hay más, no sólo no vemos otros mundos sino que tampoco vemos otras vidas que no sean la nuestra. Difícilmente podríamos tener cierta seguridad de cómo les va aquí a los otros. Destino (por llamar de alguna manera a la potencia que nos pone en el ser) reparte ciego dichas y desdichas y, si acaso un cierto barrunto de lo sabio que es que cada palo mayor aguante la vela de su barco y que con su pan se coma el navegante su salario terrenal de alegrias y tristezas. Cada visión individual del valor de la existencia encierra en sí, ciertamente, un momento de verdad, pero como expresión de cómo le va o le fue en la vida a un concreto y determinado ser humano; en la medida en que muchos otros se reconozcan en su voz, empezará su testimonio a tener un valor de verdad, intersubjetivo, pero limitado siempre a grupos de lectores más o menos amplios, nunca nada "universalmente válido». Para volver al ejemplo de las anteriores voces enfrentadas: muchos pensadores, y de los de primer orden como Freud o Wittgenstein, se rcconocen en El mundo como voluntad y representación. y de su autor ha podido decir J.L. Borges que «quizás descifró el enigma del universo»; por el contrario, las escenografías de la Teodicea de Leibniz son hoy poco más que una broma macabra o un chiste graciosísimo, posibilidades ambas que muy probablemente fue incapaz de prever en su día el inventor del cálculo infinitesimal. Además, y por si fuera poco lo que hasta aquí hemos ido examinando, hay mucha otra gente que, sin leer a estos pensadores, parecen pasárselo bastante bien y que, si se demorasen en hablar del asunto, lo que se cuidan mucho de hacer o ni siquiera se les pasa por las mientes, sin duda dirían cosas sorprendentes, aunque, la verdad sea dicha, no sé bien, ni tampoco mal, qué sorpresas nos depararían. 
Examinadas algunas de las coordenadas intelectuales que ayudan a situar históricamente el problema del sentido, quiero aproximarme al entendimiento de lo sagrado - de un concepto filosófico de lo sagradocomo fuente de sentido para nosotros contemporáneos. Estableceré primero lo que creo que son dos concepciones del sentido fundamentales en función de la relación entre la eternidad y la finitud temporal de la existencia humana. Resumo aquí mi entendimiento de las mismas para pasar luego a referirme a ellas con un poco más de detenimiento. El primero de estos hitos lo constituye el pensamiento griego tardío: la experiencia del sentido a través de la visión de lo perenne y del sosiego que esta visión produce en el filósofo; visión de lo eterno y serenidad de la vida teorética: aquí culmina la madurez de Grecia, aunque la idea platónica renuncie ya en la theoría aristotélica a concebirse como objeto eterno y al par orden eterno de la ciudad. Los ecos de esta concepción aristotélica alcanzan hasta los comienzos de los tiempos modernos por el camino señalado por el estoicismo.

Un segundo hito fundamental es la experiencia moderna -que culmina en Kant y en Goethe- de la comprensión de la experiencia humana como acción orientada por ideales a los que sólo es posible una aproximación asintótica, es decir, por ideales cuya plena realización sólo es presentida; este presentimiento viene a ser algo así como la percepción de lo perdurable en el instante (palabras de Fausto al final de la segunda parte de la obra que lleva su nombre).

Pero volvamos a Grecia y detengámonos unos momentos en la forma en que viven el problema del sentido y valor de la existencia los griegos de la época clásica. Sírveles de marco de reflexión la comparación entre la eternidad del cosmos, por una parte, y la finitud, precariedad y final caducidad de la vida individual, por otra. Que, como se ha dicho en alguna ocasión, Grecia haya sido la despreocupada juventud de la humanidad no pasa de ser una simpleza.

Graves, definitivas, irremediables suenan ya las palabras de Homero: «pasan las generaciones de los hombres como las hojas de los árboles». Píndaro llama sombra y sueño, "sueño de una sombra», a la vida humana, ${ }^{9}$ y todo lo que se diga tras él sólo podrá ser el énfasis que ponemos cuando añadimos pasión a lo que es claridad de la mente, en el error de pensar que tal claridad necesita más fuego que el que ya tiene. Erasmo coleccionó en sus Adagios tres páginas lapidarias de sentencias antiguas ${ }^{10}$ donde la primera sabiduría es la de Sileno, que recoge Nietzsche con su sólita lucidez: "Lo mejor, no nacer; si ya se está vivo, morir pronto». Para los griegos, como por lo demás para un poeta como John Keats, lo mejor es la muerte en plena juventud, la muerte en la vida aún no tocada por su lado oscuro. No se trata de Dios sabc qué upesimismo», como diría alguien que esperase de la palabra escrita un reconfortante consuelo. Se 
trata de mente, y quien dice mente o pensamiento, dice rclación primera a la verdad, y temple de ánimo para no dejar de ver lo que se ha visto.

En Platón y, sobre todo, en Aristóteles se produce un cambio muy importante; ya no se reconoce la futilidad del anhclo de duración del vivir, el énfasis se pone ahora en lo visto, en lo contemplado. Quien contempla lo eterno participa de lo eterno, la visión de lo eterno es existencia suma, y lo eterno es, para Aristótcles, el universo físico descubierto por la theoria filosófica, contemplación de un orden recurrente; los astros, que repiten sus trayectos, las especies vegetales y animales, cuyo impulso por la generación es una forma imperfecta de eternidad, y la propia visión inteligible del nous del sabio, espejo de la inteligencia ordenadora inmanente al cosmos.

Estas permanencias de lo real, esta su identidad constante confortan el ánimo del sabio estoico. De Marco Aurelio a Montaigne se nos dice una y otra vez: «quien ha visto un día ha visto cuanto hay que ver en este mundo». Lo que hay que ver es múltiple: la salida y la puesta del sol, el empecinamiento de los malvados en su ignorancia, que el emperador romano sobrelleva con paciencia, el inmenso beneficio de la sabiduría que atraviesa alegre y retozón por los Ensayos de Montaigne. Vidas tan armoniosas y ánimos tan templados que no es extraño que creyeran que les bastaban las horas de un día para conocer lo que el espectáculo del mundo ofrecía.

En los ilustrados la percepción de lo eterno se finitiza en el esfuerzo, según las conocidas palabras de Lessing prefiguradas en el Cusano: prefiero la eternidad imposible del esfuerzo incesante a la quietud del don ad. quirido de una vez por todas por gracia del Todopoderoso. En la Ilustración, ese esfuerzo tomará diversas formas: en Voltaire es la civitización que el intelectual va introduciendo poco a poco para suprimir lo que hay de bárbaro en las costumbres o la apuesta de Kant por la realizacion progresiva de los ideales morales y políticos, nunca plenamente lograda (en un incumplimiento que Kant, con su habitual sobriedad, calificará pura y simplemente de desdicha, frente a todo vacuo triunfalismo). En cuanto a Goethe creo haber dicho más arriba lo esencial de lo que tengo que decir aquí.

Entre medias, entre Grecia y el mundo moderno, ha tenido lugar un cambio radical de perspectiva, un terremoto que como dijo Gibbon provocó el hundimiento del mundo antiguo: el cristianismo. Prolongando la dirección órfico-pitagórica del pensamiento griego, fundiéndola con el judaísmo tardío y popularizando esta síntesis de Grecia y Judea que habria parecido imposible de otro modo, el cristianismo introdujo una exigencia de eternidad no para lo visto, no para la idea o el mundo físico, sino para el propio sujeto que los contempla. No supo dar un contenido comprensible a la eternidad, a su Paraíso («ver a Dios», "estar entre Dios y sus 
santos», etc.), pero introdujo una exigencia de sempiterna duración del sujeto que para los griegos no habría pasado de ser hybris, demesura. Es posible que vivamos ya - en el Occidente desarrollado- en un mundo postcristiano, pero la enormidad de esa demesura no nos ha abandonado y la comparación entre la exigencia de eternidad que tenemos en el fondo del alma y el breve tránsito por este mundo parecen haber hecho imposible cualquier experiencia del sentido que concluya en una perfecta aceptación de nuestro limitado destino. Encontrar una fuente de sentido que haga posible una aceptación profunda de nuestra existencia, aun con su fracaso último, me parece hoy una cuestión no sólo personal sino también política: o banalidad de la falta de sentido (que tantas veces se disfraza de búsqueda del éxito o del confort), o comunidad de acción orientada por el pensamiento. Tal me parece el dilema a que nos enfrentamos.

Si quisiera dar un contenido a mi propia experiencia de "lo sagrado", de las razones últimas del vivir, diría lo siguiente:

Desde el punto de vista de nuestro más legítimo anhelo, la vida es un fracaso final, pero ésta es sólo la última palabra, la que el existente nunca puede decirse a sí mismo como única palabra, pues nunca se da como esa totalidad cumplida que admitina un juicio categórico: mientras vivimos la vida ésta está, en diverso grado, abierta; cuando hemos muerto ya no somos nada.

Podemos anticipar el fin, "precursar la posibilidad más propia», si queremos decirlo heideggerianamente, pero esto sólo lo instala en el centro de nuestro existir: la nada se piensa, pero no se siente, y la angustia nos dice más bien nuestra inevitable unidad con nosotros mismos. La muerte es amenaza e inminencia aplazada y de cada momento pudo decirse que es la hora de la muerte. Pero ésta es, igualmente, nuestro más terrible rival en una lucha en la que lo que está en juego somos nosotros mismos: tenemos que alcanzar una cierta experiencia del sentido de la vida y de nuestra unidad con los seres pensantes antes de que la muerte nos alcance (creo que esta apuesta por el sentido y por su búsqueda sería válida aunque no tuviésemos ninguna seguridad de que el objeto de nuestra búsqueda existiese: es lo único que presta dignidad al empuje del mero seguir vivo y hace de él otra cosa que "instinto de conservación»). Si dejamos que la muerte nos aniquile antes de morir, si negamos toda posibilidad de algo así como un «sentido de la vida", como si la sabiduría definitiva se compendiase en las palabras del Mefisto de Goethe cuando afirma: «Pasó y la pura nada: identidad perfecta [...] Preferiría lo eternamente vacíon;" si tal cosa hiciéramos, afirmo, abririamos las puertas de la vida a la muerte, y ella reinaría en nuestra alma; daríamos por definitivamente perdida nuestra lucha, como si conociésemos la sentencia de Shakespeare: «en lo irreparable... se descansa». No tal. El gusano sí, pero en el fruto caído del árbol: no "debemos una vida a la naturaleza», como antes se 
decía. La muerte interrumpe una experiencia que, de alguna forma, se quiere eterna (eterno profundizar en el conocer, eterno sentir de las obras de arte y de los actos nobles de los hombres, eterno goce de ser que Nietzsche nos dijo que quiere la eternidad, que quiera la profunda eternidad). Pero en esta mínima participación de lo eterno, en esta experiencia finita de lo eterno es posible una vida plena de sentido. "Serán ceniza, mas tendrá sentidom, que dice Quevedo.

Pero si en lugar de negar todo valor a la vida afirmamos la dificultad, el riesgo, la aventura y el oficio de vivir encadenamos a nuestro enemiga la huesa, hacemos que nos libre sus secretos: recuerda amigo que has de morir, atiende pues al negocio de estar vivo. No aplaces, ni calles, ni temas; pues cada vez que te vencen la cobardía o la desidia no sabes si no perderás el escaso juicio que la certeza del tránsito y la brevedad del mismo te hacen tener. Nuestra poesía lo dijo ya con Jorge Manrique: recuerda, aviva el seso, despierta. Cuán inapercibida y sordamente trabaja la muerte para quien no le sale al paso.

Además, no estás solo, te acompaña la voz de Jorge Manrique, y también la de Baudelaire. Te acompañan, mucho más cerca de ti, los que resisten a la opresión y los que hablan cuando todo el mundo calla, adula o se hunde en el desánimo. Aquí estamos. Ciertamente que no elegimos este mundo nuestro y esta compañía que nuestra sociedad española nos impone, farsa y esperpento tantas veces. Pero aquí estamos. Con todos los que se esfuerzan por entender el laberinto donde hemos caído. Con quien enseña historia inteligentemente en un instituto, con quien defiende sus intereses en un sindicato, con quien traduce con pasión y rigor un libro de poemas entre diez encargos de libros deleznables. Y con quienes nos acompañan en esta tarea de investigación intelectual. Somos de aquellos que creemos que amar la vida no es un mero regalo del azar, sino algo que vamos aprendiendo día a día, con sufrimiento y goce inseparablemente unidos. Permítaseme terminar con las palabras de otro gran pocta, el francés René Char, tomadas de uno de los poemas que se incluyen en su libro Furor y misterio: "he aquí que la obscuridad se aleja y que vivir se convierte [...] en la conquista de los poderes extraordinarios de los que nos sentimos profusamente atravesados pero que sólo expresamos de forma incompleta, faltos de lealtad, de discernimiento cruel y de perseverancia».12

\section{NOTAS}

1. El autor desea expresar su agradecimiento a Carmen López Alonso por sus observaciones sobre neoconservadurismo, y a Carmen Aticnza y a Román Tamés por sus indicaciones sobre el estilo de este escrito.

2. Descartes, Discurso del Método, Primera Parte, en Oetuves et lettres, París, Gallimand, 1953, p. 127. 
3. Agapito Maestre, Modernidad, historia y politica, Estella, EVD, 1990, p. 20.

4. Carta sobre la tolerancia, Madrid, Tecnos, 1985, pp. 12-13.

5. El desencanto del mundo, Paris, Gallimard, 1985, p. 13.

6. Véase su escrito aInstitución de la sociedad y religion", en Dominios del hombre, Paris, Seuil, 1986, pp. 364-384.

7. Meditaciones, Madrid, Gredos, 1977, pp. 47-48.

8. Sobre la Revolución, Madrid, Alianza, 1988.

9. Pítica VIII, w. 95-96, en Odas y fragmentos, Madrid, Gredos, 1984, p. 194. Para una traducción diferente de estos conocidos versos de la 8. Pítica, véase M. Yourcenar, La couronne et la lyre. Poemes zraduits du grec, París, Gallimard, 1979, p. 159.

10. "Lo mejor en no nacer" incluida entre los seleccionados en la traducción incompleta de dicha obra: Erasmo, Obras escogidas, Madrid, Aguilar, 1964, pp. 1.087-1.088.

11. Fausto, en Obras, Barcelona, Planeta, 1963, II, quinto acto, p. 1.070.

12. Fureur et mystère, París, Gallimard, 1962, p. 71. 